\title{
Systemic policies towards a healthier and more responsible food system
}

\author{
Frank J van Rijnsoever, ${ }^{1}$ Harro van Lente, ${ }^{1}$ \\ Hans C M van Trijp²
}

\begin{abstract}
INTRODUCTION
Since the 1980s, the number of obese people has increased steadily across the globe. ${ }^{1}$ Consequently, more patients have serious medical conditions ${ }^{2}{ }^{3}$ such as cardiovascular diseases and type II diabetes. As a result, medical expenses increase dramatically. An important cause of obesity is unhealthy dietary habits, such as increased size of portions, eating away from home and the consumption of high-energy dense foods. ${ }^{4}$ Measures have been taken to change these dietary habits to a more responsible pattern, but with limited success.
\end{abstract}

\section{A SYSTEMIC PERSPECTIVE}

We analyse the problem from a systemic perspective, thereby acknowledging the interdependencies between the demand and the supply sides in the broader food system (see figure 1). The demand and supply sides can be viewed as sets of heterogeneous agents in which segments can be distinguished that behave differently. Segments on the demand side consist of groups of consumers that attach different meanings to food, depending on circumstances, habits and cultural conditions. ${ }^{5}$ For most people, food is more than only fuel for the body and consuming food is an enjoyable experience, which allows people to express their social values and their cultural identities. In many cultures, for example, it is a custom for hosts to show hospitability at dinner parties by presenting guests with an abundance of unhealthy but enjoyable foods.

\footnotetext{
${ }^{1}$ Innovation Studies, Copernicus Institute of Sustainable Development, Utrecht University, Utrecht, The Netherlands; ${ }^{2}$ Marketing and Consumer Behaviour Group, Wageningen University, Wageningen, The Netherlands

Correspondence to Dr Frank J van Rijnsoever, Innovation Studies, Copernicus Institute of Sustainable Development, Utrecht University, P.0. box 80115, 3508 TC, Utrecht, The Netherlands; f.j.vanrijnsoever@uu.nl
}

On the supply side, segments consist of large generalist 'multinational' companies offering a broad range of products targeted at the mass market of consumers and a large number of smaller companies offering specialised products catering to consumer segments with more specific preferences when choosing food products. ${ }^{6}$

The current situation persists because both demand and supply are faced on a daily basis with an unequal contest between short term benefits versus longterm socially responsible interests. Research has repeatedly shown that mainstream consumers often value shortterm benefits, such as low price and instant gratification (meaning high-fat, high-sugar and high-salt content), over long-term negative consequences, such as medical issues. ${ }^{7}$ The importance of price and instant gratification shapes market demand in such a manner that suppliers are forced to offer low-priced and nutritionally less desirable products through economies of scale, in order to fulfil shareholder demand or to survive in a competitive market. The result is that the supply and demand sides in the food market hold each other in a 'lock-in'. Unhealthy cheap food products are overconsumed while the supply side is forced to fulfil the market demand. ${ }^{8}$ Furthermore, different segments do not respond in a uniform manner to general policy measures. To break the lockin, coordinated policy interventions are required to change the behaviour of both demand and supply to a more socially responsible pattern.

\section{POLICY AVENUES}

To induce a switch to a healthier, socially responsible pattern, policy measures should deal with the issue of preferring short-term benefits (price, gratification or profit) over long-term costs. The boundary constraints in modern liberal societies are that the differences in preferences, norms and values among segments are respected. This means that freedom of speech, consumption and production are retained unless strong legitimisation is found to limit these rights. ${ }^{9}$ However, a liberal society can hold agents responsible for their own actions. Based on a systemic perspective on consumption and production, we delineate three generic policy routes with different specific avenues (see table 1$)^{31011}$ and argue which combination of measures is most promising.

First, the systemic interdependencies raise questions about socially responsible behaviour for demand and supply in the food system. Although the serious health issues associated with poor dietary habits on the demand side are undesirable, a focus on health alone is too narrow. Nowadays, consumption of food is interwoven with many other dilemmas, such as preparation time, environmental friendliness, animal welfare, labour conditions in the production chain, and so on. Based on their own norms and values, consumers need to balance these aspects with health, price and instant gratification. Companies, in turn, face many other dilemmas. Next to fulfilling market demand, firms deliver profit to shareholders, employ people, contribute to economic growth and are increasingly expected to make a contribution to society. ${ }^{12}$ To solve the problem effectively, where possible, consensus should be reached at a system level among stakeholders about minimum standards for responsible products. This is the lowest level of general agreement; we call them system norms, like the ones that already exist for safety. These norms can be maintained through binding regulations that change the availability of products or through voluntary agreements between suppliers. This type of policy does not rely on consumers taking responsibility and works only if sufficient consensus exists about system norms and if alternative products are available.

Next to the agreed system norms, agents are free to decide what products are socially responsible. However, given the varying meanings attached to food by different segments, it is unlikely that the system norms will include long-term health standards. Therefore, additional measures need to be taken to change consumption and production.

The second route is to regulate information flows to the demand side; these measures retain freedom of consumption, but do not hold consumers directly responsible for their behaviour. Furthermore, this route deals with neither price nor gratification. The first avenue is to add 


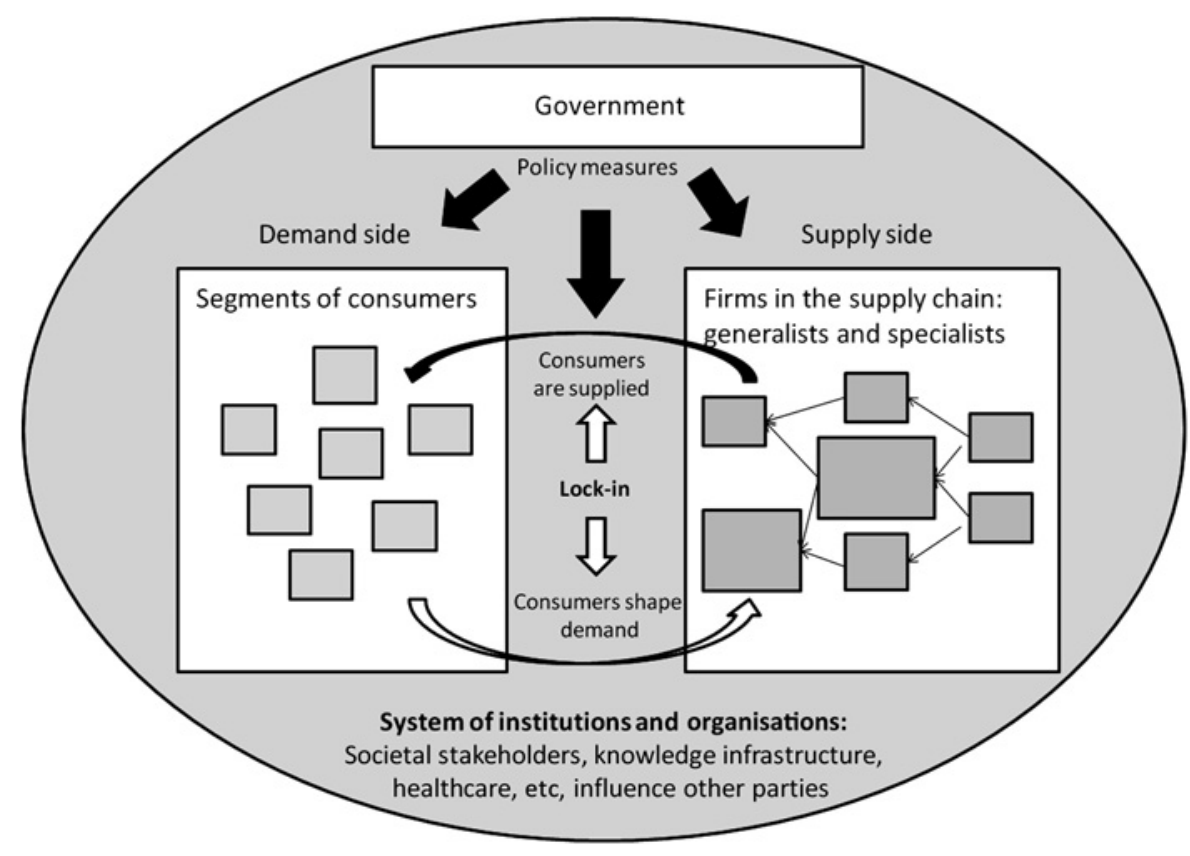

Figure 1 A representation of the locked-in food system.

information to the system, although information campaigns are targeted at specific segments. Information can be provided in the retail situation through product packages. However, making a responsible choice means considering the many aspects discussed above based on the inconsistent information provided by different stakeholders. The space available on product packages is limited, which makes it nearly impossible for the consumer to make a well-informed choice. Here, innovative IT solutions can be applied like the development of SmartPhone applications by independent intermediaries to inform the consumer about products in the retail situation. Another solution could be to withdraw information from the system by forbidding certain communications (eg, advertisements). Although this partly contributes to solving the problem, it also impedes freedom of speech and is therefore likely to encounter legal barriers. ${ }^{9}$ Thus, everyone can add information to the system, but removal is problematic.

The third route is to change incentives for consumption and production. A first avenue is to reward responsible consumption, for example, by subsidising healthy food products. For consumers it becomes more attractive to purchase these products and producers are more likely to offer them to the market. However, research has shown that this measure is ineffective, because consumers spend the budget saved through subsidies on unhealthy alternatives. ${ }^{3}$

Another avenue is making suppliers responsible for their products by charging them extra for irresponsible foods. Producers can compensate for this by charging consumers extra for their products (although not necessarily the irresponsible ones) or by implementing cost savings, for example, by sobering labour conditions or by reducing investments in new product development. Thereby responsibility can be avoided, which makes this avenue problematic.

A more promising avenue is to charge consumers for the societal costs associated with irresponsible consumption, for example, through a 'Fat Tax'. ${ }^{13}$ This type of policy is legitimised by the fact that consumers are held responsible for their irresponsible behaviour towards society, while freedom of consumption is retained. For producers, offering 'untaxed' healthy alternatives becomes relatively more attractive, although this does not guarantee that these alternatives will actually be made available. Healthy alternatives need to be present to preserve consumer freedom of choice. The money raised through such a measure thus needs to be invested in the development of new alternatives and in covering increased medical expenses. A further problem is that for this radical measure stakeholder support needs to be gathered. ${ }^{11}$

Table 1 An overview of the policy routes and avenues

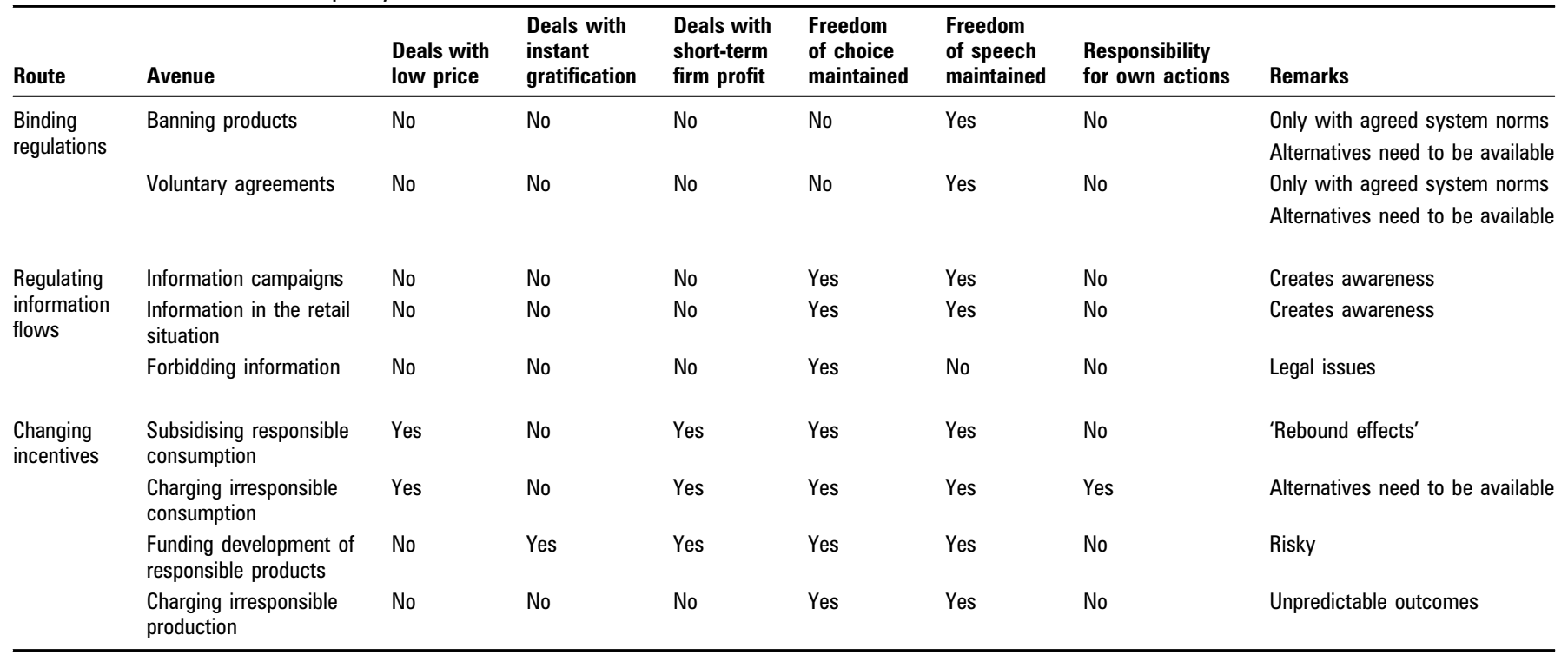


This avenue deals with price but not with gratification. The latter can be taken into account by developing new products that provide the same amount of gratification, but that do not have negative health consequences or other downsides; a promising example here seems to be the use of nanotechnology. Although the innovation option bears much potential, it is also the least secure one. Many resources are needed and suppliers must exchange certain short-term profits for uncertain long-term benefits. It is unknown whether the newly engineered products are trusted by consumers and whether they meet the requirements for enjoyment sufficiently. Such uncertainties hamper innovation. To reduce these risks, governments can support firms (possibly collaborating with universities) by providing funds to develop these innovative products.

Overall, the most promising approach is to combine charging irresponsible behaviour on the demand side with stimulating responsible product development on the supply side. This approach deals best with the problem of valuing short-term benefits over long-term costs, while not violating the boundary conditions of a liberal society. In order to create awareness among different segments of consumers, information provision plays a supporting role. Over time, this can lead to shifts in system norms, which will provide the legitimisation for further policies that will in turn stimulate the transition towards a more responsible food system.

Funding This research was funded by the Socially Responsible Innovation programme of the Dutch Science Foundation (NWO).

\section{Competing interests None}

Provenance and peer review Commissioned; not externally peer reviewed.

J Epidemiol Community Health 2011;65:737-739. doi:10.1136/jech.2011.141598

\section{REFERENCES}

1. Finucane MM, Stevens GA, Cowan MJ, et al. National, regional, and global trends in body-mass index since 1980: systematic analysis of health examination surveys and epidemiological studies with 960 country-years and $9 \cdot 1$ million participants. Lancet 2011;377:557-67.

2. Haslam DW, James WP. Obesity. Lancet 2005;366:1197-209.
3. Willyard C. Lifestyle: breaking the cancer habit. Nature 2011:471:S16-17.

4. Hensrud DD. Diet and obesity. Curr Opin Gastroenterol 2004;20:119-24.

5. Korthals M. Before Dinner: Philosophy and Ethics of Food. Amsterdam: Boom, 2002.

6. Hannan MT, Freeman J. Organizational Ecology. Cambridge, MA: Harvard University Press, 1989.

7. Hoch SJ, Loewenstein GF. Time-inconsistent preferences and consumer self-control. J Consum Res 1991;17:492-507.

8. van Rijnsoever FJ. Two important issues when promoting healthier food. Lancet 2011;377:1240.

9. Mermin SE, Graff SK. A legal primer for the obesity prevention movement. Am J Public Health 2009;99:1799-805.

10. Nayga RM Jr. Nutrition, obesity and health: policies and economic research challenges. Eur Rev Agr Econ 2008;35:281-302.

11. González-Zapata LI, Alvarez-Dardet C, Millstone E, et al. The potential role of taxes and subsidies on food in the prevention of obesity in Europe. $\checkmark$ Epidemiol Community Health 2010:64:696-704.

12. Campbell JL. Why would corporations behave in socially responsible ways? An institutional theory of corporate social responsibility. Acad Manage Rev 2007;32:946-67.

13. Mytton 0, Gray A, Rayner M, et al. Could targeted food taxes improve health? J Epidemiol Community Health 2007;61:689-94.

\section{Journal of Epidemiology and Community Health alerts}

Sign up for our electronic table of contents alerts and you will never miss new issues of Journal of Epidemiology and Community Health when published online. Stay ahead and up to date by visiting jech.bmj.com. 